\title{
Marie d'Agoult/Daniel Stern, eroina romantica e intellettuale europea, a cura di Laura Colombo e Franco Piva
}

\section{Valentina Ponzetto}

\section{(2) OpenEdition \\ 1 Journals}

\section{Edizione digitale}

URL: http://journals.openedition.org/studifrancesi/8984

DOI: ERREUR PDO dans /localdata/www-bin/Core/Core/Db/Db.class.php L.34 : SQLSTATE[HY000]

[2006] MySQL server has gone away

ISSN: 2421-5856

\section{Editore}

Rosenberg \& Sellier

\section{Edizione cartacea}

Data di pubblicazione: 1 octobre 2008

Paginazione: 478-479

ISSN: 0039-2944

\section{Notizia bibliografica digitale}

Valentina Ponzetto, «Marie d'Agoult/Daniel Stern, eroina romantica e intellettuale europea, a cura di Laura Colombo e Franco Piva», Studi Francesi [Online], 155 (LII | II) | 2008, online dal 30 novembre 2015, consultato il 08 janvier 2021. URL: http://journals.openedition.org/studifrancesi/8984 ; DOI: https:// doi.org/10.4000/studifrancesi.8984

Questo documento è stato generato automaticamente il 8 janvier 2021.

\section{(†)

Studi Francesi è distribuita con Licenza Creative Commons Attribuzione - Non commerciale - Non opere derivate 4.0 Internazionale. 


\title{
Marie d'Agoult/Daniel Stern, eroina romantica e intellettuale europea, a cura di Laura Colombo e Franco Piva
}

\author{
Valentina Ponzetto
}

\section{NOTIZIA}

Marie d'Agoult/Daniel Stern, eroina romantica e intellettuale europea, a cura di Laura CoLOMBO e Franco PIVA, «Nuovi Quaderni del C. R. I. E. R.», anno III, 2006, pp. 204.

1 Scrittrice, ideologa, intellettuale di respiro veramente europeo, Marie d'Agoult è oggi troppo spesso dimenticata o confinata nell'immagine oltremodo semplicistica e riduttiva di musa ed eroina romantica, compagna e ispiratrice di Franz Liszt. Salutiamo dunque con gioia questo numero monografico dei «Nuovi Quaderni del C. R. I.E. R.» che rende giustizia e omaggio ad una personalità tutta da riscoprire, rinnovando il legame privilegiato fra la scrittrice e l'Italia, da lei considerata una «patrie d'élection». Il volume pubblica gli atti della Giornata internazionale di studi organizzata, fedele alla sua vocazione di «Centro di Ricerche sull'Italia nell'Europa Romantica», e tenutasi all'Università di Verona il 2 dicembre 2005, in occasione del bicentenario della nascita della contessa. I diversi aspetti dalla vita, dell'opera, del pensiero e della fortuna di questa intellettuale cosmopolita si rispecchiano in undici interventi di altrettanti specialisti, improntati ad una grande apertura pluridisciplinare e internazionale.

2 L'introduzione di Franco PIVA (Marie d'Agoult, un personaggio complesso di dimensione europea, pp.7-17) ripercorre la biografia di Marie, evocando, al di là delle sue burrascose vicende personali, la natura e l'importanza delle sue opere, pubblicate sotto lo pseudonimo di Daniel Stern, il suo pensiero progressista, figlio della filosofia dei Lumi e teso alla difesa delle donne e del popolo, la sua partecipazione alle vicende politiche tanto francesi quanto italiane. 
3 Seguono quindi due saggi in cui l'avvicinamento della contessa alla scrittura e i suoi esordi letterari sono seguiti attraverso il rapporto con due figure di spicco nella sua vita e nella cultura del tempo: Sand e Liszt. In George Sand, modello letterario invocato poi rinnegato da Marie d'Agoult (pp.19-35), Annarosa PoLI ripercorre la storia dell'amicizia, dell'ammirazione e della rivalità fra le due romanziere, restando felicemente al di sopra di ogni sterile polemica per sottolineare invece le influenze reciproche, in un percorso di ispirazione, identificazione e rinnegamento altamente fecondo. Ancora più delicato è il tema del rapporto di Marie con Liszt. Luciano CHIAPPARI, biografo del musicista, fa con obbiettività il punto Sull'autore delle "Lettres d'un bachelier ès musique": Liszt e Marie d'Agoult (pp. 37-60). Il suo intervento ricostruisce con precisa documentazione lo stato dell'annosa questione dell'apporto dell'uno e dell'altra alle famose lettere, mettendo in risalto la sostanziale complementarietà e la comunanza di sentire tra i due artisti.

Con il saggio di Béatrice DIDIER, Marie d'Agoult romancière (pp.60-72), si entra nel vivo dell'opera di Daniel Stern con una finissima lettura del suo primo romanzo, Nélida. Dopo aver ridotto alle giuste proporzioni la parte autobiografica dell'opera, la studiosa ne analizza le ascendenze letterarie e la qualità della scrittura, invitando in conclusione a rivedere gli schemi della storia letteraria per far posto ad una romanziera che meriterebbe pienamente di esservi inclusa. Biografa e principale studiosa italiana della contessa, Laura соцомво ci propone poi un denso intervento frutto delle sue lunghe ricerche negli archivi di Versailles e nelle carte inedite della d'Agoult. Des "Notes sur Mme de Staël" aux notes inédites de Versailles: passion et féminisme dans les rapports de Mme d'Agoult avec ses filles et avec les femmes de son temps (pp. 73-88) propone infatti da un lato una presentazione e un'analisi dell'inedito saggio su Mme de Staël, ora finalmente in corso di stampa nell'edizione critica della stessa L. Colombo; dall'altro un quadro dei rapporti epistolari intrattenuti da Marie con le sue figlie e con altre donne più o meno celebri del tempo. Ne emerge il ritratto di una pioniera del femminismo, attenta all'educazione della donna e al suo ruolo nella società. Il saggio è seguito dalla trascrizione (pp. 89-100) di alcune lettere, in parte inedite, relative al soggetto trattato. Ancora sull'epistolario della contessa verte l'intervento di Charles DUPECHEZ, che puntualizza lo stato dei lavori della «Publication de la correspondance générale de la comtesse d'Agoult» (pp.101-104), pubblicazione di cui egli stesso è curatore e che fornirà senza dubbio un prezioso documento sulla politica, la cultura e la società del XIX secolo.

5 L'ultima parte del volume si apre invece alla letteratura comparata e alla storia, esplorando i rapporti di Marie d'Agoult con diversi paesi europei. L'ispanista Antonella GALLO ricostruisce le circostanze e il clima culturale della traduzione spagnola di Nélida (Mariano Urrabieta Vierge e la traduzione spagnola di "Nélida"», pp. 105-119), mentre Olga KAFANOVA traccia il panorama della Réception russe de Daniel Stern (pp.121-134) tanto dal punto di vista delle traduzioni, che da quello della critica letteraria o dell'influenza sugli scrittori russi. Giselinde SEYBERT analizza inversamente gli articoli di Marie d'Agoult dedicati alla letteratura tedesca apparsi sulla «Revue des deux Mondes»: quello su Heine e Freiligart, che testimonia la posizione d'avanguardia della critica di Daniel Stern, quello su Dante e Goethe, e soprattutto quello complesso e contraddittorio su Bettina Brentano (Marie d'Agoult/Daniel Stern et ses ambiguités face à la littérature allemande, pp. 135-144). Infine gli ultimi due articoli esplorano i rapporti della contessa con il Risorgimento italiano. Marie d'Agoult e il Risorgimento: alcune lettere inedite a Felicita Bevilacqua La Masa, di Elena SOLDINI (pp.145-165), presenta l'inedito carteggio con la 
patriota veronese e mette in luce il ruolo da lei giocato al tempo del soggiorno di Marie a Torino nel 1860; mentre Marie d'Agoult e la storiografia del suo tempo di Gian Paolo ROMAGNANI (pp.167-189) rivisita l'opera storica della scrittrice, certo carente di una sistematica filosofia della storia, ma forte delle lezioni di Michelet, di un'amplissima documentazione e di uno scrupolo di obiettività che ne fanno, in particolare, una delle migliori testimonianze sulla rivoluzione del 1848.

6 Come sottolineano i curatori, una simile ricchezza di prospettive non può che invitare a nuovi e più approfonditi studi su Marie d'Agoult, scrittrice e prezioso specchio del suo tempo. 